\title{
Spray Combustion Chamber: History and Future of a Unique Test Facility
}

\author{
Andreas Schmid ${ }^{\star 1}$, Naoki Yamada ${ }^{1}$ \\ ${ }^{1}$ Future Technologies, Winterthur Gas \& Diesel Ltd., Switzerland \\ *Corresponding author: andreas.schmid@wingd.com
}

\begin{abstract}
Large marine two-stroke diesel engines still represent the major propulsion system for merchant shipping. With steadily increasing transport demands, rising operational costs and stricter environmental legislations, the global marine shipping industry finds itself facing the challenge to future-proof its fleet. In order to comply with international maritime organizations emission standards (TIER II and TIER III), highly sophisticated and flexible combustion systems are demanded. With the help of spray and combustion research such systems can be developed and continuously improved. A highly valuable tool to investigate sprays of large marine diesel injectors under engine relevant conditions is the Spray Combustion Chamber (SCC). This paper reviews the history of the SCC, shows todays possibilities and looks into the near future of research involving large marine two-stroke engines. The SCC was built during the first Hercules project (I.P.-HERCULES, WP5, [1]). The initial setup focused on fundamental investigations comprising the application of highly flexible thermodynamic conditions. During follow-up projects (Hercules beta [2] and Hercules C [3]) the SCC was continuously developed, and a variety of influences on spray and combustion were experimentally assessed. The initial SCC design focused on maximum optical access as well as the applicability of a wide span of optical techniques. Single-hole nozzles were utilized to generate reference data to optimize existing spray and combustion simulation models. Different fuel types and fuel qualities were investigated and effects of the in-nozzle flow on spray morphology was identified. A sound set of results was achieved and published in several (internal and public) reports. Over the years, spray research at Winterthur Gas \& Diesel has turned its focus from basic spray investigations to more detailed cavitation and in-nozzle flow examinations [4], [5]. Future research on the SCC will focus on investigations of more engine related topics, as, for example, the application of a fuel flexible injection system as is currently developed in the HERCULES-2 project [6]. Significant design modifications of the initial setup were necessary, as the injector positions and therefore exposure of the spray relative to the swirl were not fully congruent with real engine conditions. As a consequence, the new setup includes some minor drawbacks, e.g. the optical access of the nozzle tip is only visible from one side of the chamber. This means that line-of-sight methods are currently only possible at selected positions in the centre of the chamber. Therefore, a new setup was installed to illuminate the spray, consisting of a high speed, high energy laser $(100 \mathrm{kHz}, 100 \mathrm{~W})$ and special optics. In order to obtain enhanced optical access, tangential windows were rearranged, now pointing directly at the nozzle. With this setup, a first set of images was realized, showing a real spray as it occurs in large marine two-stroke diesel engines.
\end{abstract}

\section{Keywords}

Large marine diesel engines, spray, combustion, high pressure high temperature conditions, heavy fuel oil, residual fuel

\section{Introduction}

Due to their high thermal efficiency and reliability, Diesel engines are still relied upon extensively for seaborne freight transport. With steadily increasing transport demands, rising operational costs and increasing environmental restrictions, the global marine shipping industry finds itself facing the challenge to future-proof its fleet. Ship owners and operators are looking for alternative fuels in order to remain economically competitive while complying with strict environmental regulations. Today's injection systems already are capable of handling a variety of fuel qualities, ranging from light fuel oils to residual fuels of very high viscosity and density. Nevertheless, in order to provide even higher fuel flexibility, injection systems are designed to facilitate the injection of fuels with for example very poor self-ignition properties or poor lubricity.

To develop such an injection system, highly sophisticated tools are required: From state of the art injection- and component test rigs up to full scale test engines (e.g. RTX-6, located in Winterthur, Switzerland). 


\section{The past}

Before the SCC was built, experimental data, regarding spray and combustion of large marine diesel engines was scarce. Especially for common rail type engines - also for large marine diesel engines a cornerstone - the injection behaviour could only be estimated based on up-scaled models from (much!) smaller experiments. This lack of data lead to a great partnership between several stake holders: In close collaboration with ETH Zürich and PSI Villigen, a setup was designed, developed and established which still represents state-of-the-art.

The SCC was built during the first Hercules project, IP-HERCULES (WP5, [1]). The setup allowed for fundamental spray and combustion investigations (fundamental in the context of industrial research) with highly flexible thermodynamic conditions and impeccable optical access. Unlike a specific test engine, pressure, temperature and swirl can be adjusted almost independently, while on a (large marine two-stroke) test engine variations of pressure and temperature can only be achieved by changing the compression ratio or the scavenge air temperature. This gives the possibility to investigate combustion under conditions which are out of the scope of the classic compression curve of an engine. Figure 1 shows the schematic of the initial SCC design.

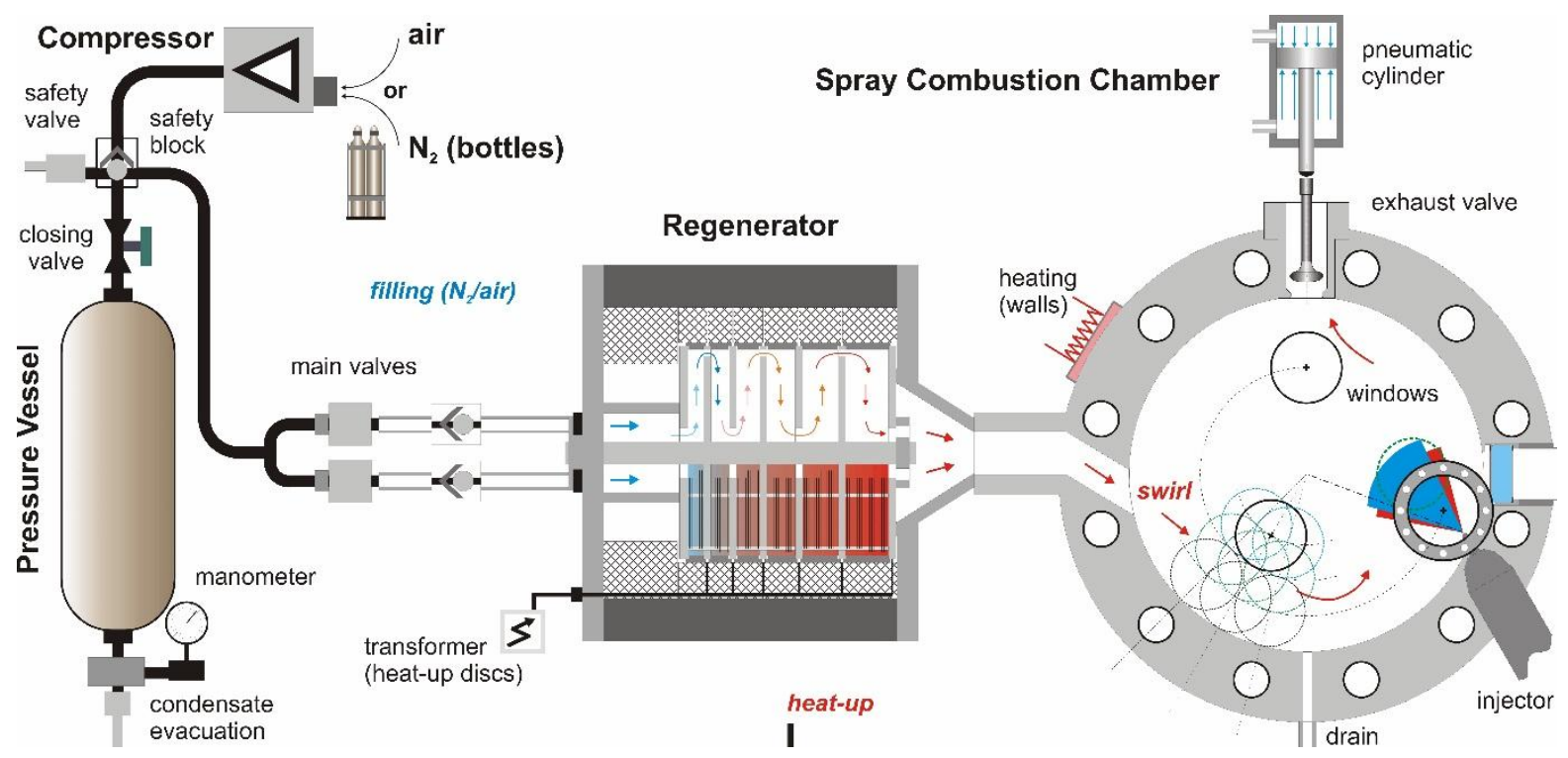

Figure 1: Schematic drawing of the entire test facility setup, also indicating operation phases such as heat up of the process gas or swirl production as well as functional aspects (window position, exhaust valve, etc.) [7]

The field of operation of the SCC is much larger compared to any constant volume chamber. The principle consists of three main parts:

a) Pressure vessels

These can be filled with nitrogen, air or a mixture of inert gases and oxygen in order to simulate EGR conditions for example. Fast acting valves control the pressure in the SCC: starting from a minimum filling time of about $150 \mathrm{~ms}$ up to $1000 \mathrm{~ms}$ to reach 140 bar chamber pressure. From the pressure bottles, the inert gas flows through the

b) Regenerator

The so-called regenerator is actually a large surface which heats the process gas and allows for process gas temperature between $300 \mathrm{~K}$ up to $940 \mathrm{~K}$, depending on the pressure and swirl conditions aimed for. The pressurised and/or hot gas then feeds the main chamber, the

c) SCC main body

This disc shaped volume represents the volume and geometric dimensions of a medium sized twostroke marine diesel engine. The process gas is introduced via tilted inlet ports into the chamber producing the characteristic swirl. The swirl velocity is a function of time. By setting a different timing of the injection event, different swirl velocities can be accomplished. The main body itself consist of three pieces:

i. A cover, representing the piston

ii. The ring section, representing the liner

iii. A second cover (mirrored), representing the engines cylinder cover 
The three pieces are held together by $50 \mathrm{~mm}$ bolts. The two covers are independently rotatable by steps of $15^{\circ}$.

The optical access is granted via three sapphire windows featuring an optical width of $100 \mathrm{~mm}$. The three windows are mounted on individual radial positions on the cover. In combination with the rotational freedom, the complete area of the SCC can be observed. Additionally, three smaller windows in the ring section - pointing to the centre of the combustion chamber - allow for optical access from the side. The left image in Figure 2 shows the setup before the installation of the control system. Well visible in the front is the SCC main body. The right side of the image shows the common rail system and the Injection Control Unit (ICU) mounted on top of the fuel rail (yellow). This is a standard injection system as found on a serial engine.
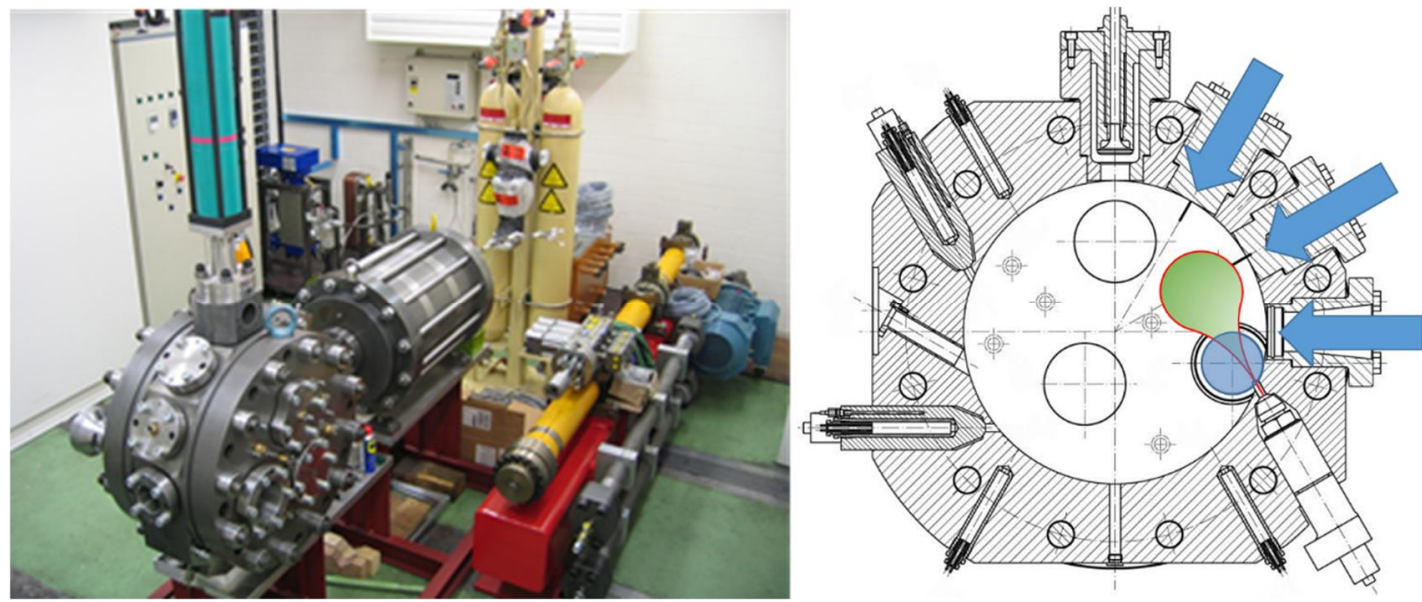

Figure 2: Installation in the laboratory, short before finalization (left), sectional view with optical accesses from the side indicated with arrows (right)

The fuel valve is a standard injector, instrumented with a needle lift sensor, as well as a pressure sensor, measuring the pressure before the nozzle. The injector is mounted on the SCC main body at an angle of $30^{\circ}$ from the vertical axis. The nozzle tip, in most cases, is a single-hole nozzle with co-axial layout as indicated on Figure 2 , right side.
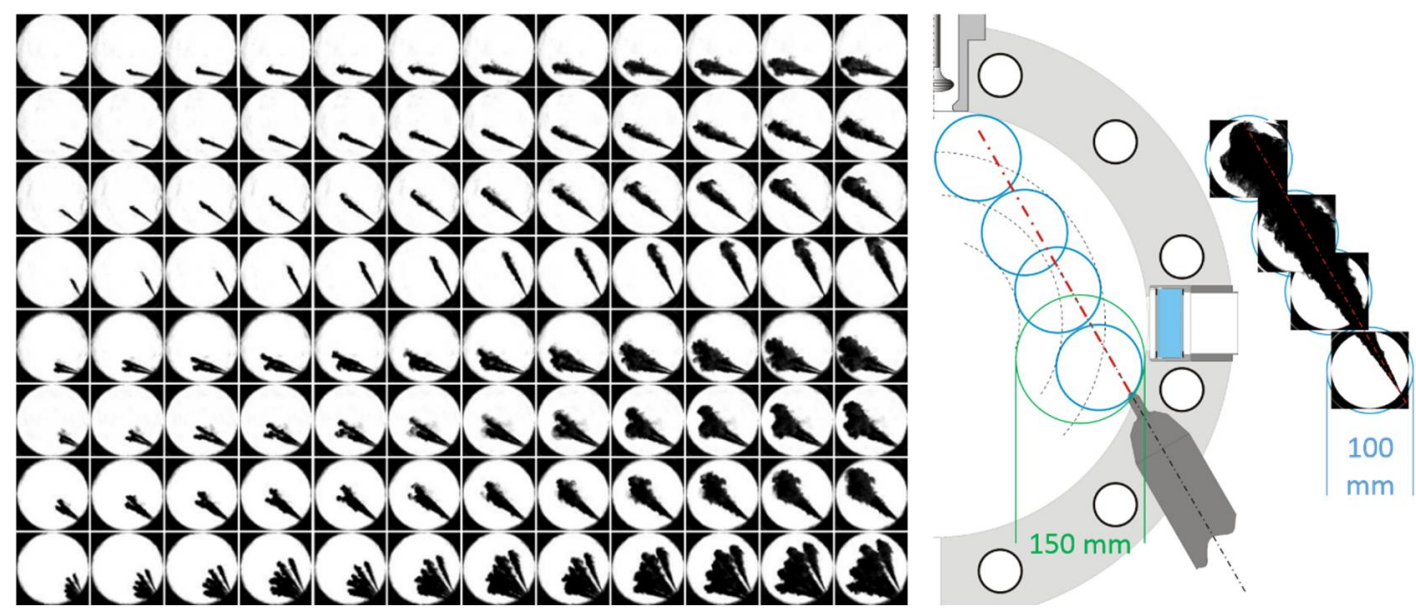

Figure 3: Extract of the different spray investigations [8] (left side) and an example of different window positions, necessary to follow the spray [9]

The setup was extensively used to produce data of sprays at different conditions, as can be seen in Figure 3 (left side). Due to the size of the spray compared to the optical access of the chamber, investigations of the complete spray are very time consuming: Including the time needed to heat up the system, pump up the pressure vessels and cleaning the windows, a single experiment can take up to 20 minutes. For each spray, several window positions were required to record the complete spray, as can be seen at the right side of Figure 3 . In the first version of the SCC the covers had to be rotated to change the window position. The rotation of the $500 \mathrm{~kg}$ (each) disks took about 
half a day as the setup had to be taken apart, rotated and reassembled again. The interested reader can estimate the effort to make spray investigations with the first design: It was tremendous.

In the following projects (HERCULES-B [2], HERCULES-C [3]) the SCC was continuously improved and extended, while various influences on spray and combustion have been experimentally assessed, as several internal and external publications proof [7], [8][10],[14][18]. Windows with increased optical width - eccentrically arranged in a large window-holder - allowed for wider spray areas to be observed and much quicker change of the window position. The green circle in Figure 3 (right side) illustrates the increased diameter of the windows, compared to the blue circles of the initial design.

The larger windows provide maximum optical access and support the application of a wide span of optical techniques such as: Shadow imaging, Mie scattering, Phase Doppler Anemometry or $\mathrm{OH}^{*}$-chemiluminescence. However, harsh combustion conditions and the size of the experimental setup called for ... adaptions of measurement techniques to properly investigate typical effects on spray and ignition. For example, during combustion, soot incandescence is so strong that it easily outshines the background illumination applied for shadow imaging. The solution was an "improved shadow imaging" setup, consisting of a laser emitting at $640 \mathrm{~nm}$ in combination with a narrow band pass filter before the camera. The result can be seen in Figure 4: The image, acquired with the classic setup, is dominated by the light from soot incandescence, whereas the spray on the right side - for the same thermodynamic conditions, at the same time after SOI -is clearly visible.

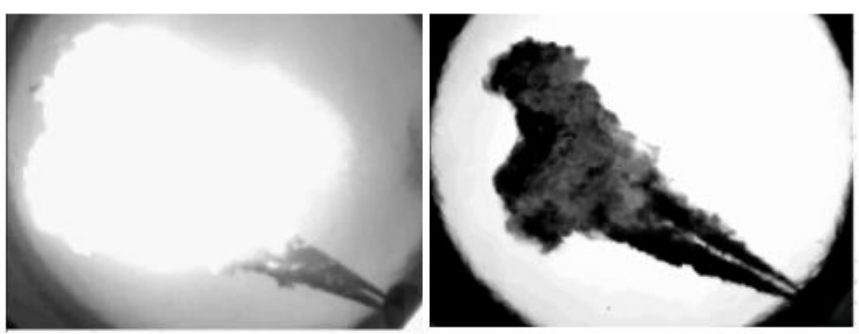

Figure 4: Classic shadow imaging (left) compared to the improved shadow imaging (right)

The same problem occurred for $\mathrm{OH}^{*}$ chemiluminescence; As presented in Ref. [10] radiation from soot fully hides $\mathrm{OH}^{*}$ chemiluminescence shortly after ignition. In order to distinguish between UV light from the $\mathrm{OH}$ radical and light from soot radiation, both signals were captured and $\mathrm{OH}^{*}$ could be detected in the beginning of the combustion. Droplet size measurement by means of Phase Doppler Anemometry (PDA) under these conditions is even more complicated, especially investigating an opaque fluid. Therefore, a study was made to design the ideal setup to do so: The result is a tailor-made PDA system as described in Ref.[11], allowing to measure droplet sizes with PDA in the harsh environment of the SCC, even with heavy fuel oil. With the focus of in-nozzle flow special illumination techniques have been compared to assess the spray very close to the nozzle [12].

With single hole nozzles, reference data for the optimisation of spray and combustion simulations has been generated [8], [9], [13],[14],[15],[16],[17]. Different fuel types and fuel qualities have been investigated on their spray behaviour, ignition characteristics and combustion [18]. With special nozzles effects of the in-nozzle flow on spray morphology have been identified [19], [20]. Between 2010 and 2015 a detailed and comprehensive analysis of spray and combustion of large marine diesel sprays under the presence of swirl flow [21] was performed.

\section{The present}

Today the SCC comes in a complete new dress, with a main chamber design representing the actual combustion chamber geometry of an engine. To investigate nozzle tips with the same orifice orientation as on the engine, the cylinder cover follows real engine specifications. With the RTX-6 test engine next door to the SCC, its cylinder cover design was taken to guarantee best agreement with engine measurements. By doing so, the SCC can be considered as an optical access to the combustion space of the RTX-6 test engine - except for some limitations like the $100 \%$ load case (which is not fully applicable due to the high peak pressure). Nevertheless, the orientation and position of the injectors is exactly the same as on the engine. Figure 5 shows the sketch of the new main body with all injector positions occupied with standard injectors (left). The right side shows the actual installation. 

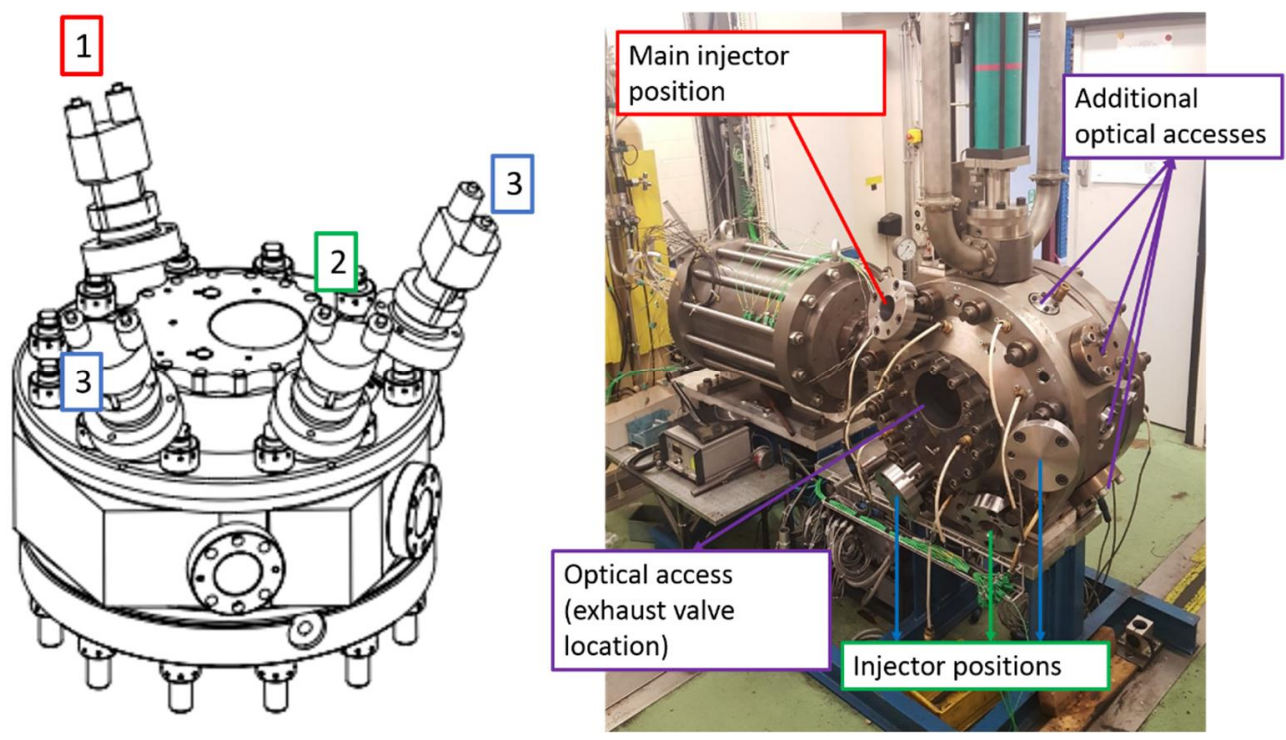

Figure 5: New SCC main body with cover of the test engine (RTX-6)

Well visible are the adapters on the injector positions " 3 ". All the adapters were made larger than the actual injector, so that also future injector designs can fit todays body: Individual adapters fit any actual (and most probably future) injector to be tested on the SCC, without re-machining the main body. The injector positions without injector are closed with so called dummies. The four possible injector positions are divided in:

1) The main injector

2) A secondary injector for the two-injector setup (setup on smaller two-stroke engines)

3) Two additional injectors for the three-injector setup (setup on large and very large two-stroke engines).

Where in the real engine the exhaust valve would be located, the SCC has an eccentric window holder with a sapphire window of $150 \mathrm{~mm}$ optical width. This allows the observation of the centre of the combustion chamber. The back side of the SCC - the piston side - is closed with one of the existing covers, allowing to observe the complete combustion chamber.

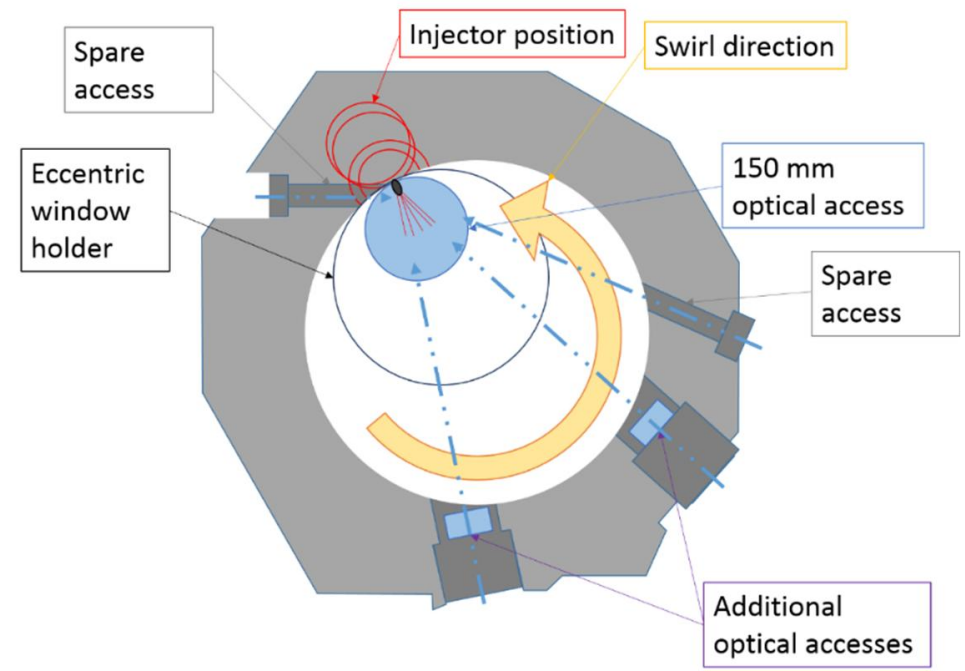

Figure 6: Sectional view with optical accesses from the side

Another distinct modification compared to the initial arrangement is the orientation of additional optical accesspossibilities. As visible in Figure 2, the windows located in the ring section of the SCC are all pointing to the centre of the main body. This restricts the application of measurement techniques which are based on laser sheets to illuminate the spray. Laser Induced Fluorescent measurement methods were therefore only applicable in a very limited way. The new setup has the additional windows not pointing to the centre of the chamber anymore, as can 
be seen in Figure 6: To illuminate the spray with laser light, the additional optical accesses are pointing to the tip of the injector. This allows the observation of the spray origin from the side and/or enables the admission of a laser (sheet) for the application of Mie scattering techniques to illuminate the liquid phase of the spray or even LIF-based methods. The smaller holes from the side of the chamber are for the so called spare accesses. These holes are intended for additional measurement techniques like fibre optics or can be used to additionally illuminate the spray (additional light from the side or an additional laser wavelength for excitation) which might be implemented in the future.

A very first spray investigation has been conducted with the new setup: As a reference case the injection with a standard fuel nozzle has been chosen, under conditions as they are found at about $25 \%$ engine load. Figure 7 shows a series of spray images, from SOI until the fully developed flame is visible.
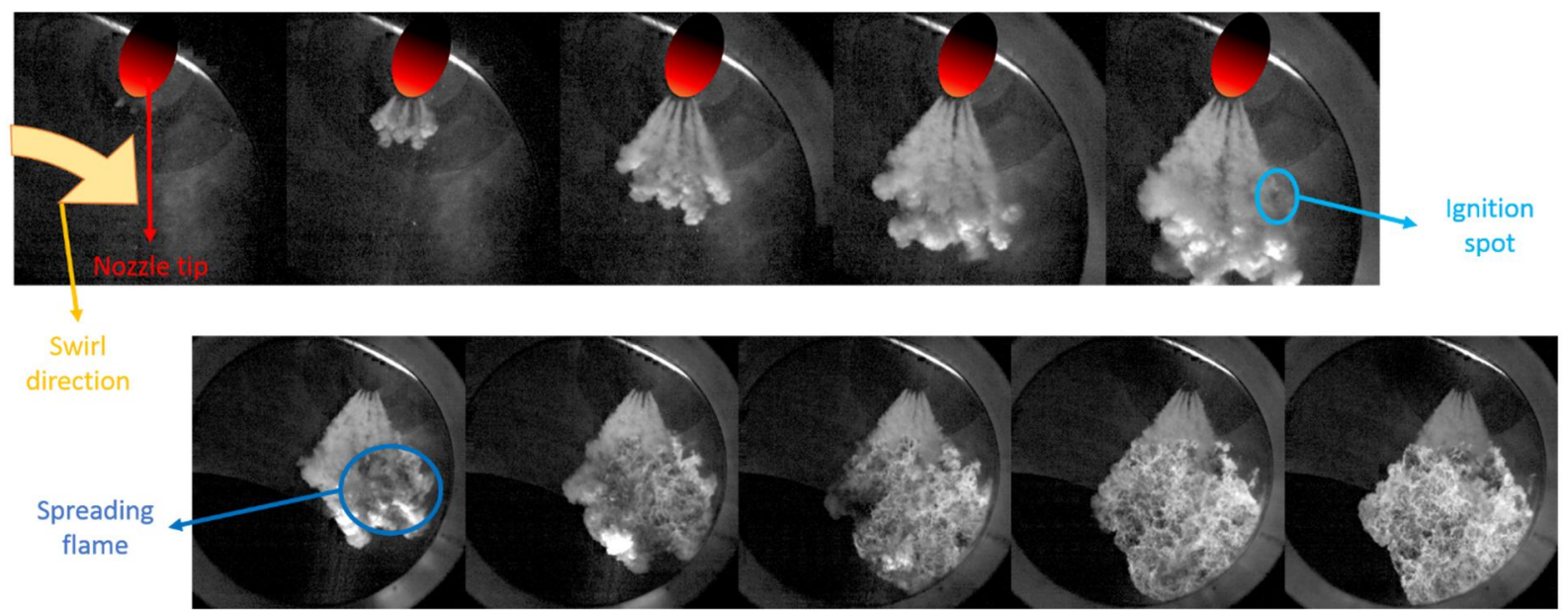

Figure 7: Example of a real sized spray nozzle under engine like conditions

Unlike in smaller engines, the spray pattern is not symmetric, as already discussed in earlier investigations looking at eccentric sprays ([19], [20]). To allow for maximum scavenging efficiency, the exhaust valve is located in a centred position of the cylinder. Therefore, the fuel injectors are protruding from the side into the combustion chamber. The swirl, coming from the left side, pushes the leading fuel portions to the side. This effect is more evident when looking at the flame: Instead of an even distribution of the flame, it is pushed out of the visible area into the lower right corner. On the lower left side, no flame can therefore be seen. Compared to the investigations from the single-hole nozzles another interesting fact can be observed: The rather narrow arrangement of the fuel orifices produces 5 individual sprays, very early during the injection. But after a certain progress of the spray, these single sprays seem to merge to a single spray front, acting as one large spray/flame volume.

\section{The future}

Even though the SCC has been adapted to apply engine relevant injection systems, basic spray and combustion research still represents a fundamental requirement: $A$ detailed investigation has started to understand the interrelation between in-nozzle flow, cavitation, spray breakup - by means of Ballistic Imaging - spray morphology, ignition and combustion. This research will partly take place in the laboratory under non-evaporating, no-swirl conditions and later transfer this knowledge into the SCC, where the spray morphology, ignition and combustion will be assessed.

For the HERCULES-2 project [6] research on the SCC will focus on more engine relevant problematics, as for example the application of a fuel flexible injection system. Future injection systems are designed to provide full flexibility with regards to fuel qualities and the operation of classic fuels like HFO and MDO as well as on fuels with very low viscosity or ignitability like ethanol or methanol. Such systems could not have been tested on the initial setup, as the injector position was not optimised for such investigations and the adaption of the main body would have been too costly.

The new main body on the SCC also included the installation of a new illumination setup, consisting of a high speed, high energy laser $(100 \mathrm{kHz}, 100 \mathrm{~W})$ and special optics. The very short illumination pulses of 2 ns allow not only the pin sharp visualisation of the spray within the SCC, but should also visualize the fast exiting spray close to the orifice as suggested in earlier works [12]. 


\title{
Conclusions
}

Ten years ago, a worldwide unique experimental setup, allowing for the investigation of large scale marine diesel sprays under engine relevant conditions, has been taken into service. Since then the installation has been improved with respect to optical access, fuel flexibility and reduction of service time. In parallel its sphere of action has been continuously increased, from the investigation of spray morphology and combustion to a device which allows for the examination of small quantities of alternative fuels, new injection systems or new injection strategies with a variety of measurement techniques. Over the years also several measurement methods have therefore been adapted and improved in order to be applied under the demanding conditions of large marine diesel engines.

Now the next chapter in the life of the SCC has been opened, the application of real engine hardware to establish the direct link between irreplaceable measurements on test engines and the possibility to access the combustion with highly sophisticated methods and measurement techniques.

A very first series of experiments showed the successful application of the new setup and already helped to better understand combustion under these demanding and unique conditions.

In the future, this new setup will directly help to improve combustion of different fuels, support the development of combustion systems and methods and therefore do one's bit in the reduction of exhaust emissions, increase of fuel flexibility and efficiency.

\section{Acknowledgements}

The installation of such a complex setup would not have been possible without the support of several partners over the past years. The design, setup and continuous improvement of the SCC has been conducted within the framework of different projects:

- $\quad$ I.P. HERCULES project within EC's 6th Framework Program: Contract TIP3-CT-2003-506676

- $\quad$ HERCULES- $\beta$ project within EC's 7th Framework Program: Contract SCP7-GA-2008-217878

- $\quad$ HERCULES-C project within EC's 7th Framework Program: Contract SCP1-GA-2011-284354

- HERCULES-2 project within European Union's Horizon 2020 research and innovation programme under grant agreement No 634135

The additional financial support by the Swiss Federal Government during several projects:

- Contract 154269, Project 103241,

- SFOE Contract SI/500940, TP Nr 8100075, Project name "FlexFuel Combustion"

- SFOE Contract SI/501299-01, TP Nr 8100075, Project name "INFLOSCOM"

is gratefully acknowledged.

Over the past years, a fantastic collaboration has been established with and among the different partners. The sincere thank therefore goes to the experts and people who took part in the long journey and are still invaluable allies:

- $\quad$ ETH Zürich

- PSI Villigen

- $\quad$ EMPA Dübendorf

- $\quad$ FHNW Brugg-Windisch

- IFPEN Paris

- NTUA Athens

- Chalmers University of Technology Gothenburg

\author{
Abbrevations \\ EGR Exhaust Gas Recirculation \\ EMPA Eidgenössische Materialprüfanstalt \\ FHNW Fachhochschule Nordwestschweiz \\ ETH Eidgenössische Technische Hochschule \\ HFO Heavy Fuel Oil \\ ICU Injection Control Unit \\ IFPEN Institut Français du Pétrole, Energie Nouvelle \\ LIF Laser Induced Fluorescence \\ MDO Marine Diesel Oil \\ NTUA National Technical University of Athens \\ PSI Paul Scherrer Institute \\ SCC Spray Combustion Chamber \\ SOI Start Of Injection \\ WinGD Winterthur Gas \& Diesel Ltd.
}




\section{References}

[1] IP-HERCULES, www.ip-HERCULES.com

[2] HERCULES-B, www.HERCULES-B.com

[3] HERCULES-C, www.HERCULES-C.com

[4] C. Habchi, J. Bohbot, A. Schmid, K. Herrmann, A comprehensive Two-Fluid Model for Cavitation and Primary Atomization Modelling of liquid jets - Application to a large marine Diesel injector, CAV2015, 9th International Symposium on Cavitation, Lausanne, Switzerland, 6-10 December 2015.

[5] Balz R., "In-nozzle flow and spray morphology investigations of marine diesel injectors", Poster, ECCOMATE 1st Conference on Combustion Processes in Marine and Automotive Engines, 07. to 08.06.2016, Lund, Sweden

[6] HERCULES-2, http://www.hercules-2.com/work-package-1

[7] Herrmann K., Schulz R., Weisser G., „Development of a reference experiment for large diesel engine combustion system optimization", Paper No. 98, CIMAC Congress 2007, Vienna

[8] Herrmann K., von Rotz B., Schulz R., Weisser G., Boulouchos K., Schneider B., „Reference Data Generation of Spray Characteristics in Relation to Large 2-Stroke Marine Diesel Engines Using a Novel Spray Combustion Chamber Concept", ILASS - Europe 2010, Brno, Czech Republic

[9] von Rotz B., Herrmann K., Weisser G., Cattin M., Bolla M., Boulouchos K., „Impact of Evaporation, Swirl and Fuel Quality on the Characteristics of Sprays typical of Large 2-Stroke Marine Diesel Engine Combustion Systems", ILASS - Europe 2011, Estoril, Portugal

[10] Schmid A., von Rotz B., Bombach R., Weisser G., Herrmann K., Boulouchos K., „Investigation of Marine Diesel Ignition and Combustion at Engine-Like Conditions by means of $\mathrm{OH}^{*}$ Chemiluminescence and Soot Incandescence", Paper No. Cl-8, COMODIA 2012, Fukuoka, Japan

[11] von Rotz B., Kammermann T., Schneider B., Schmid A., Herrmann K., Weisser G., Boulouchos K., „Evaluation of PDA Applicability in Regard to Heavy Fuel Oil Spray Investigations”, $17^{\text {th }}$ International Symposium on Applications of Laser Techniques to Fluid Mechanics, Lisbon, Portugal, 07-10 July, 2014

[12] Schürch C., "Evaluation of Spray Visualization Techniques for the Investigation close to the Orifice", Master thesis, ETH Zürich 2014

[13] Schulz R., Herrmann K., von Rotz B., Hensel S., Seling F., Weisser G., Wright Y.M., Bolla M., Boulouchos K., „Assessing the Performance of Spray and Combustion Simulation Tools against Reference Data Obtained in a Spray Combustion Chamber Representative of Large Two-Stroke Diesel Engine Combustion Systems“, Paper No. 247, CIMAC Congress 2010, Bergen

[14] Herrmann K., "Entwicklung, Validierung und erste Anwendung eines neuartigen Brennkammer-konzepts für die Generierung von Referenzdaten hinsichtlich der Charakterisierung des Einspritz-vorganges in Bezug auf grosse 2-Takt Schiffsdieselmotoren“, 1. GMT Rostock, Deutschland

[15] Herrmann K., von Rotz B., Schulz R., Weisser G., Schneider B., Boulouchos K., „A "Spray Combustion Chamber" facility for investigations in relation to large 2-stroke marine diesel engine combustion system optimization", Abstract of the International Symposium on Marine Engineering (ISME), 2011, Kobe, Japan

[16] Bolla M., Cattin M.A., Wright Y.M., Boulouchos K., Schulz R., „3D-CFD Lagrangian Spray Simulations for Large Two Stroke Marine Diesel Engines compared with Experimental Data of a Spray Combustion Chamber", ASME ICES2012-81016, Torino, Italy

[17] Nagy, I. G., Schmid, A., et al., Computational analysis of spray primary breakup in 2-stroke marine diesel engines with different nozzle layouts, ICLASS 2015, 13th Triennial International Conference on Liquid Atomization and Spray Systems, Tainan, Taiwan, August 23-27, 2015, Tainan, Taiwan

[18] Schmid A., von Rotz B., et al. Ignition behaviour of marine diesel fuels under engine like conditions, SAE 2014 International Powertrain, Fuels \& Lubricants Meeting, October 2014, Birmingham, UK

[19] Schmid, A., von Rotz, B., Schulz, R., et al., Influence of nozzle hole eccentricity on spray morphology, ILASS - Europe 2013, 25th European Conference on Liquid Atomization and Spray Systems, 1-3 Sep. 2013, Chania, Greece

[20] Schmid, A., Von Rotz B., et al. Influence of in-nozzle flow on spray morphology, ILASS - Europe 2014, 26th Annual Conference on Liquid Atomization and Spray Systems, 8-10 Sep. 2014, Bremen, Germany

[21] von Rotz, B., Experimental Investigation of Spray Characteristics and Ignition Processes at Conditions representative of Large Two-Stroke Marine Diesel Engines. Dissertation, ETH Zürich, 2015, No. 22968 (2015). http://dx.doi.org/10.3929/ethz-a-010836986 